\title{
Níveis de Lisina para Leitoas com Alto Potencial Genético para Deposição de Carne Magra dos 65 aos $95 \mathrm{~kg}^{1}$
}

\section{João Luís Kill² ${ }^{2}$ Juarez Lopes Donzele ${ }^{3}$, Rita Flávia Miranda de Oliveira ${ }^{3}$, Aloízio Soares Ferreira ${ }^{3}$, Darci Clementino Lopes ${ }^{3}$, Francisco Carlos de Oliveira Silva ${ }^{4}$, Marcos Vinícius Gualberto Barbosa da Silva ${ }^{5}$}

\begin{abstract}
RESUMO - Foram utilizadas 216 leitoas híbridas comerciais, da mesma linhagem genética, com alto potencial para deposição de carne magra na carcaça com peso médio inicial de $66,3 \pm 4,24 \mathrm{~kg}$ e final de $95,5 \pm 2,05 \mathrm{~kg}$, para avaliar o efeito de níveis de lisina da dieta. Os animais foram distribuídos em delineamento experimental de blocos ao acaso, com quatro tratamentos, 27 repetições e dois animais por unidade experimental. Os tratamentos corresponderam a dietas isoenergéticas, com diferentes níveis de lisina total ( 0,$80 ; 0,90 ; 1,00$; e $1,10 \%$ ), obtidos por alterações nas proporções de milho e farelo de soja da dieta. Não foi observado efeito dos tratamentos sobre o ganho de peso diário, a taxa de crescimento em músculo e conversão alimentar em músculo. Houve efeito quadrático dos tratamentos sobre o consumo de dieta, que reduziu até o nível estimado de $0,95 \%$, e a conversão alimentar, que melhorou até o nível de $0,97 \%$ de lisina. Observou-se efeito linear dos níveis de lisina sobre a taxa de deposição de proteína, que aumentou, e sobre a taxa de deposição de gordura, que reduziu com o aumento dos níveis de lisina na dieta. Não foi verificado efeito dos tratamentos sobre as características de comprimento de carcaça, a espessura de toucinho na região entre a última e a penúltima vértebra lombar, a espessura de toucinho a $6,5 \mathrm{~cm}$ da linha dorsolombar $\left(\mathrm{P}_{2}\right)$, o rendimento de carcaça, o rendimento de carne magra, o rendimento de gordura e o rendimento de pernil. Concluiu-se que leitoas geneticamente selecionadas para alta taxa de deposição de carne magra exigem 0,97\% de lisina total, correspondente ao consumo diário de 24,24 g de lisina e a 0,29\% de lisina total/Mcal de EM, para melhor conversão alimentar. Para maior taxa de deposição de proteína, os dados indicam que a exigência está acima de $1,1 \%$ de lisina total.
\end{abstract}

Palavras-chave: desempenho, fase de terminação, genótipo, lisina

\section{Lysine Levels for Gilts with High Genetic Potential for Lean Meat Gain from 65 to $95 \mathrm{~kg}$}

\begin{abstract}
Two hundred and sixteen crossbred gilts with high genetic potential for lean meat gain, with average initial weight of $66.3 \pm 4.24 \mathrm{~kg}$ and final weight of $95.5 \pm 2.05 \mathrm{~kg}$, were used to evaluate the effect of lysine levels on animals performance in the finishing phase. A randomized block design was used with four treatments, 27 replicates and two animals per experimental unit. Treatments were constituted of isoenergy diets, with different levels of total lysine $(0.80,0.90,1.00$, and $1.10 \%)$, obtained by changes on corn and soybean meal proportion. There was no treatment effect on daily weight gain, muscle growth rate and muscle feed:gain ratio. There was a quadratic effect of dietary lysine on feed intake, which decreased up to the level of $0.95 \%$ lysine, and on feed:gain ratio, which increased up to the level of $0.97 \%$ lysine. There was a linear effect of lysine levels on protein and fat deposition rate, that respectively, increased and reduced with dietary lysine levels. There was no effect of treatments on carcass length, backfat thickness measured between the last and last but one lumbar vertebra, backfat thickness at $6.5 \mathrm{~cm}$ from the midline carcass, carcass yield, lean meat yield, fat yield and ham yield. It was concluded thatgilts with high genetic potential for lean meat gain require $0.97 \%$ of total lysine, that correspond to a daily intake of $24.24 \mathrm{~g}$ of lysine for best feed:gain ratio. Data show that to the highest protein deposition rate the requirement is above of $1.1 \%$ of total lysine.
\end{abstract}

Key Words: finishing phase, genotype, lysine, performance

\section{Introdução}

Para satisfazer as exigências de mercado e aumentar a produção de ganho em carne magra, pesquisas na área de melhoramento genético de suínos vêm sendo desenvol- vidas com o intuito de melhorar a taxa de crescimento, a eficiência alimentar, o desempenho em produção de músculo e composição da carcaça, a redução na deposição de gordura. Entretanto, para que isso ocorra, as exigências nutricionais dos suínos devem ser alteradas.

\footnotetext{
${ }^{1}$ Parte da tese de Doutorado apresentada à UFV. Projeto apoiado pela AGROCERES.

${ }^{2}$ Professor da UVV. E.mail: jlkill@ig.com.br

3 Professor do DZO/UFV. E.mail: donzele@mail.ufv.br

4 Pesquisador EPAMIG-CRZM.

5 Pesquisador da EMBRAPA.
} 
Do ponto de vista nutricional, o padrão de deposição de gordura em suínos pode ser alterado em função do sexo, do adequado consumo de energia, do uso de dietas corretamente balanceadas em aminoácidos, entre outros (Campabadal \& Navarro, 1997; Bellaver \&Viola, 1997).

Suínos com alta taxa de ganho protéico requerem, diariamente, maiores quantidades de aminoácidos, principalmente lisina, para maximizar seu desempenho e a taxa de deposição de proteína na carcaça (Friesen et al., 1994; Stahly et al., 1994). Sabe-se que a lisina é considerada o primeiro aminoácido limitante em dietas para suínos à base de milho e farelo de soja, sendo diretamente responsável pelo aumento na deposição de músculo na carcaça. Assim, as respostas de desempenho e deposição de carne magra na carcaça podem ser associadas ao nível de lisina da dieta (Yen et al., 1986).

A exigência de lisina, para suínos de ambos os sexos, nas diferentes fases do ciclo produtivo, pode ser influenciado pelo nível protéico das dietas, pelos sistemas de alimentação, pela capacidade genética dos animais e pela relação entre a lisina e os demais aminoácidos limitantes (Easter \& Baker, 1980; Stahly et al., 1991).

A introdução de diferentes genótipos especializados na produção de carne magra na carcaça e com elevadas taxas de crescimento, nas unidades produtoras de suínos, fez com que as necessidades diárias de lisina desses animais fossem alteradas (Schinckel, 1994). Assim, o estabelecimento de uma alimentação específica, para os diferentes genótipos, tornou-se preocupação constante para os nutricionistas.

O NRC (1998) e Rostagno et al. (2000) sugerem níveis diferenciados de lisina, para leitoas em crescimento e terminação, de acordo com seu potencial genético para deposição de carne magra na carcaça, de forma que diferentes planos de nutrição possam ser estabelecidos para os diferentes genótipos.

Considerando-se a escassez de informações na literatura brasileira, com respeito aos requerimentos nutricionais de lisina para suínos com alto potencial genético para deposição de carne magra, é importante que se realizem mais estudos, principalmente com respeito ao estabelecimento correto da exigência de lisina, para que os mesmos atinjam o ótimo desempenho.

O objetivo desta pesquisa foi avaliar níveis de lisina total da dieta para leitoas com alto potencial genético para produção de carne magra, dos 65 aos $95 \mathrm{~kg}$ de peso.

\section{Material e Métodos}

O experimento foi realizado nas instalações da granja de melhoramento genético do Departamento de Zootecnia da Universidade Federal de Viçosa, localizada no município de Viçosa, Minas Gerais.

Foram utilizadas 216 leitoas híbridas comerciais, da mesma linhagem genética, selecionadas para produção de carne magra, com peso médio inicial de 66,3 $\pm 4,24 \mathrm{~kg}$, distribuídas em um delineamento experimental de blocos ao acaso, com quatro tratamentos $(0,80 ; 0,90 ; 1,00$ e $1,10 \%$ de lisina total $), 27$ repetições e dois animais por baia. A baia com dois animais foi considerada a unidade experimental. Para a distribuição dos animais dentro de cada bloco, adotou-se, como critério, o peso inicial e o parentesco dos animais. Os blocos foram formados no tempo.

As dietas experimentais foram formuladas à base de milho e farelo de soja, com $3.300 \mathrm{kcal}$ de EM, para atender as exigências dos animais segundo Rostagno et al. (2000), com níveis de lisina variando de acordo com a proporção de milho e farelo de soja da dieta, resultando em dietas com 0,80; 0,90; 1,00 e 1,20\% de lisina total.

As composições centesimal e calculada das dietas são apresentadas na Tabela 1 . O fornecimento de dieta e água foi à vontade.

Para determinação dos parâmetros ganho de peso, consumo de ração, conversão alimentar e consumo de lisina, foram feitas pesagens semanais das rações e respectivas sobras, e dos animais, no início e no final do experimento, quando atingiram o peso médio de 95,5 $\pm 2,05 \mathrm{~kg}$.

Os animais foram alojados em baias equipadas com comedouros semi-automáticos e bebedouros tipo chupeta, com piso de concreto e cobertura de telha de cimento amianto.

Para registrar a temperatura diária, foi utilizado termômetro de máxima e mínima colocado no interior do galpão.

Ao atingirem o peso de abate, dez animais de cada tratamento, com peso médio de 95,01 $\pm 2,27 \mathrm{~kg}$, foram abatidos após jejum alimentar de 24 horas e de água nas últimas 12 horas. $\mathrm{O}$ abate foi feito por dessensibilização e sangramento. Em seguida, os animais foram depilados com lança-chamas e as carcaças evisceradas. As carcaças inteiras, incluindo pés e cabeça, foram pesadas e, após serradas longitudinalmente, as meias carcaças foram pesadas separadamente. 
Tabela 1 - Composição centesimal, química e energética das dietas experimentais Table 1 - Centesimal, chemical and energy composition of the experimental diets

\begin{tabular}{|c|c|c|c|c|}
\hline \multirow[t]{2}{*}{$\begin{array}{l}\text { Ingredientes }(\%) \\
\text { Ingredients }\end{array}$} & \multicolumn{4}{|c|}{$\begin{array}{c}\text { Níveis de lisina }(\%) \\
\text { Lysine levels }\end{array}$} \\
\hline & 0,80 & 0,90 & 1,00 & 1,10 \\
\hline Milho (Corn) & 72,99 & 68,94 & 64,84 & 60,78 \\
\hline Farelo de soja (Soybean meal) & 20,90 & 24,70 & 28,50 & 32,26 \\
\hline Fosfato bicálcico (Dicalcium phosphate) & 2,05 & 2,05 & 2,05 & 2,05 \\
\hline Calcário (Limestone) & 1,10 & 1,05 & 1,05 & 1,05 \\
\hline Óleo de soja (Soybean oil) & 1,90 & 2,20 & 2,50 & 2,80 \\
\hline Sal comum (Salt) & 0,40 & 0,40 & 0,40 & 0,40 \\
\hline Mistura mineral (Mineral mix $)^{1}$ & 0,25 & 0,25 & 0,25 & 0,25 \\
\hline Mistura vitamínico (Vitamin mix $)^{2}$ & 0,35 & 0,35 & 0,35 & 0,35 \\
\hline Antibiótico $(\text { Antibiotic })^{3}$ & 0,05 & 0,05 & 0,05 & 0,05 \\
\hline Antioxidante (Antioxidant) (BHT) & 0,01 & 0,01 & 0,01 & 0,01 \\
\hline \multicolumn{5}{|l|}{ Composição calculada (Calculated composition) } \\
\hline Proteína bruta (Crude protein) (\%) & 15,60 & 17,00 & 18,42 & 19,82 \\
\hline Energia metabolizável (kcal/kg) (Metabolizable energy) & 3.300 & 3.300 & 3.300 & 3.300 \\
\hline Lisina total $(\%)$ (Total lysine) & 0,800 & 0,900 & 1,000 & 1,100 \\
\hline Treonina total $(\%)$ (Total threonine) & 0,536 & 0,572 & 0,609 & 0,645 \\
\hline Met + Cis. total $(\%)($ Total Met + Cys $)$ & 0,624 & 0,679 & 0,733 & 0,787 \\
\hline Triptofano total (\%) (Total tryptophan) & 0,203 & 0,226 & 0,249 & 0,271 \\
\hline Cálcio (Calcium) (\%) & 0,985 & 0,985 & 0,985 & 0,985 \\
\hline Fósforo total (Total phosphorus) (\%) & 0,498 & 0,498 & 0,498 & 0,498 \\
\hline
\end{tabular}

Para determinação da composição da carcaça dos suínos, no início do experimento, cinco animais da mesma linhagem daqueles utilizados nesse experimento, com peso médio de $64,83 \pm 2,42 \mathrm{~kg}$, foram abatidos conforme descrito anteriormente.

Para determinação das taxas de deposição de proteína e de gordura, a banda direita foi triturada durante 20 minutos em "CUTTER" comercial de 30 HP e 1775 rotações por minuto. Após homogeneização, foram retiradas amostras de aproximadamente $1 \mathrm{~kg}$, que foram armazenadas em freezer a $-12^{\circ} \mathrm{C}$, para serem analisadas posteriormente.

As taxas de deposição de proteína e de gordura nas carcaças foram calculadas comparando-se as composições das carcaças dos animais no início e no final do experimento.

A fim de se retirar o excesso de água e de gordura das amostras, elas passaram por um processo de présecagem em estufa com ventilação forçada, a $60^{\circ} \mathrm{C}$, por 96 horas e, em seguida, foram pré-desengorduradas pelo método a quente, por quatro horas, em extrator tipo "SOXHLET". A água e a gordura, retiradas durante o preparo inicial das amostras, foram consideradas para correções dos valores das análises subseqüentes.
Após os processos de pré-secagem e prédesengorduramento, as amostras foram finamente moídas em moinho de bola, acondicionadas em recipientes de vidro com tampa e conservadas em geladeira, para análises posteriores.

As análises de proteína bruta e extrato etéreo das amostras foram realizadas segundo metodologia descrita por Silva (1990).

As bandas esquerdas, incluindo a cauda, foram colocadas em câmara fria $\left(4\right.$ a $\left.8^{\circ} \mathrm{C}\right)$, onde permaneceram por 24 horas, enquanto as medidas lineares da carcaça foram feitas logo após serem serradas. Para o espostejamento, foram utilizadas quatro meias carcaças (esquerda) dos animais abatidos em cada tratamento.

As medidas de comprimento de carcaça, rendimento de carcaça e área de olho de lombo foram avaliadas utilizando a metodologia descrita pela Associação... (1973). A espessura de toucinho na região entre a última e a penúltima vértebra lombar; a espessura de toucinho a $6,5 \mathrm{~cm}$ da linha dorso-lombar (P2); e os rendimentos de carne magra (expressos pelo peso total de carne na carcaça em relação ao peso total da carcaça dissecada), de gordura (expressos 
como peso da gordura total da carcaça em relação ao peso da meia carcaça resfriada) e de pernil (expressos como percentual do peso total do pernil, em relação ao peso da meia carcaça resfriada) foram realizados segundo as técnicas utilizadas pela indústria brasileira.

Para avaliação da taxa de crescimento em músculo (TCM) e da conversão alimentar em músculo (CAM), foram usados os pesos médios inicial (PMI) e final (PMF) dos animais, peso da carcaça quente (PCQ), peso médio da meia carcaça esquerda (PMCE), peso médio da meia carcaça esquerda fria (PMCEF), rendimento de carne magra (RCM), rendimento de carcaça (RC) e rendimento de frigorificação (RF).

A determinação do RC e do RF foi realizada de acordo com as seguintes expressões (Fowler et al., 1976):

$$
\mathrm{RC}=\mathrm{PCQ} / \mathrm{PMF} \times 100
$$

$$
\mathrm{RF}=\mathrm{PMCEF} / \mathrm{PMCE} \times 100
$$

Os cálculos de TCM e CAM foram feitos utilizando-se as expressões sugeridas por Fowler et al. (1976):

$$
\mathrm{TCM}=(\mathrm{MFT}-\mathrm{MIT}) / \mathrm{PE}
$$

$\mathrm{CAM}=\mathrm{CA} /(\mathrm{RC} \times \mathrm{RF} \times \mathrm{RCM}) \times 10^{-6}$

em que: MFT (músculo no final do teste) $=$ PMF $x$ RC x RF x RCM x 10-6; MIT (músculo no início do teste) $=0,418 \times$ PMI (lb) - 3,650, de acordo com NPPC (1991), citado por Ellis (1998); e PE = duração do período experimental.

Análise econômica

A análise econômica foi feita utilizando-se o conceito de índice de rentabilidade (IR) ou rentabilidade simples (Buarque, 1991). O IR foi determinado de acordo com a seguinte expressão:

$$
I R=\left(\sum_{i=1}^{n} Y i \times P-\sum_{i=1}^{n} C O N R i \times P R i\right) / \sum_{i=1}^{n} C O N R i \times P R i
$$

em que: $\mathrm{IR}=$ índice de rentabilidade; $\mathrm{Y}_{\mathrm{i}}=$ peso do animal no tratamento $\mathrm{i} ; \mathrm{P}=$ preço por $\mathrm{kg}$ do animal; CONRi = consumo de dieta no tratamento $\mathrm{i}$; e $\mathrm{PRi}=$ preço do $\mathrm{kg}$ da dieta do tratamento $\mathrm{i}$.

Os preços utilizados na determinação dos custos das rações foram fornecidos por uma empresa comercial. Quanto aos preços dos suínos, foram usados os recebidos pelo produtor na granja, no período de janeiro a fevereiro de 1999.

As variáveis de desempenho, características de carcaça e taxas de deposição de proteína e gordura foram analisadas pelo Sistema de Análises Estatísticas e Genéticas - SAEG (UFV, 2000), versão 8.0, utilizando os procedimentos para análises de variância e regressão.

R. Bras. Zootec., v.32, n.6, p.1647-1656, 2003 (Supl. 1)

\section{Resultados e Discussão}

As médias das temperaturas mínimas e máximas, registradas durante todo o período experimental, foram, respectivamente, $23,9 \pm 1,34^{\circ} \mathrm{C}$ e $28,6 \pm 1,86^{\circ} \mathrm{C}$.

Os resultados de ganho de peso, consumo de ração, conversão alimentar, consumo de lisina, taxa de crescimento em músculo e conversão alimentar em músculo são apresentados na Tabela 2.

O consumo de ração diário (CRD) foi influenciado de forma quadrática $(\mathrm{P}<0,05)$ pelo nível de lisina da dieta, tendo reduzido até o nível estimado de $0,95 \%$ (Figura 1). Este resultado diferiu daqueles obtidos por Donzele et al. (1994), Pimenta et al. (1995) e Fontes et al. (2000), que não verificaram alteração no CRD de leitoas em terminação, devido a variação no nível de lisina da dieta.

Mesmo tendo ocorrido redução no $\mathrm{CRD}$, até o nível de $0,95 \%$ de lisina, o ganho de peso dos animais não foi comprometido, o que pode ser explicado pelo fato de o consumo de lisina diário ter aumentado $(\mathrm{P}<0,01)$ de forma linear (Tabela 2 ) entre os tratamentos. Respostas de aumento de consumo de lisina, em função da concentração deste aminoácido nas dietas, têm sido constatadas também por outros autores (Friesen et al., 1995; Souza, 1998; Fontes et al., 1999), embora Gomes et al. (1998) não tenham verificado variação no consumo de lisina quando a concentração desse aminoácido na dieta aumentou de 0,90 para $1,05 \%$.

$\mathrm{O}$ aumento no CRD verificado no nível mais alto de lisina $(1,10 \%)$, não era esperado se for considerado que nos diferentes níveis de lisina, a concentração dos demais aminoácidos essenciais, em relação a lisina, não ficou abaixo daquela recomendada na proteína ideal, proposta por Fuller (1996), e que a concentração de lisina na proteína praticamente não variou $(5,12$ a $5,55 \%)$.

Não se observou efeito $(\mathrm{P}>0,05)$ dos níveis de lisina da dieta sobre o ganho de peso diário (GPD) dos animais. Este resultado foi semelhante ao obtido por Donzele et al. (1994), que não constataram variação no ganho de peso de leitoas em terminação em função do nível de lisina da dieta, e com os resultados obtidos por Fontes (1999) que, avaliando níveis de lisina entre 0,75 e $1,15 \%$ para leitoas de genótipos superiores, de alto potencial para produção de carne magra, também não observou alteração no ganho de peso dos animais. De forma contrária, diversos autores (Cromwell et al., 1993; Friesen et al., 1995; Yen et al., 1996; Souza, 
Tabela 2 - Médias estimadas das variáveis de desempenho de leitoas (65 aos $95 \mathrm{~kg}$ ), recebendo dietas com níveis crescentes de lisina

Table 2 - Estimated means of performance variables of gilts (65 to $95 \mathrm{~kg}$ ) fed diets with increasing lysine levels

\begin{tabular}{|c|c|c|c|c|c|}
\hline \multirow[b]{2}{*}{$\begin{array}{l}\text { Variáveis } \\
\text { Variables }\end{array}$} & \multicolumn{4}{|c|}{$\begin{array}{c}\text { Níveis de lisina da ração (\%) } \\
\text { Dietary lysine levels }\end{array}$} & \multirow[b]{2}{*}{$\mathrm{CV}(\%)$} \\
\hline & 0,80 & 0,90 & 1,00 & 1,10 & \\
\hline $\begin{array}{l}\text { Consumo de ração diário }{ }^{1}, \mathrm{~g} \\
\text { Daily feed intake }\end{array}$ & 2567 & 2449 & 2425 & 2557 & 8,50 \\
\hline $\begin{array}{l}\text { Ganho de peso diário, } \mathrm{g} \\
\text { Daily weight gain }\end{array}$ & 939 & 944 & 957 & 955 & 7,13 \\
\hline $\begin{array}{l}\text { Conversão alimentar }{ }^{1} \\
\text { Feed:gain ratio }\end{array}$ & 2,74 & 2,59 & 2,55 & 2,68 & 8,02 \\
\hline $\begin{array}{l}\text { Consumo de lisina diário }{ }^{2}, \mathrm{~g} \\
\text { Daily lysine intake }\end{array}$ & 20,54 & 22,04 & 24,25 & 28,13 & 8,64 \\
\hline $\begin{array}{l}\text { Taxa de crescimento em músculo }(\mathrm{g} / \mathrm{d}) \\
\text { Muscle growth rate }\end{array}$ & 498 & 493 & 499 & 497 & 2,28 \\
\hline $\begin{array}{l}\text { Conversão alimentar em músculo } \\
\text { Feed:muscle gain ratio }\end{array}$ & 5,59 & 5,57 & 5,51 & 5,77 & 3,93 \\
\hline
\end{tabular}

1997) constataram variação no GPD das leitoas em terminação, em função do nível de lisina da dieta.

As diferenças de resultados entre os trabalhos acima citados podem estar relacionadas, entre outros fatores, ao nível de lisina utilizado na dieta basal, uma vez que nos trabalhos em que foram verificadas variações no GPD o nível máximo de lisina total utilizado na dieta basal foi de $0,60 \%$, enquanto nos trabalhos em que não se verificou variação no GPD, o nível de lisina utilizado ficou acima deste valor.

Os níveis de lisina influenciaram $(\mathrm{P}<0,01)$ a conversão alimentar (CA), que variou de forma quadrática e melhorou até o nível de 0,97\% (0,29\%/Mcal de EM) de lisina (Figura 2), correspondente a um consumo diário estimado de $24,23 \mathrm{~g}$ de lisina.

Os resultados obtidos estão em acordo com aqueles de Fontes (1999), que também encontrou efeito quadrático dos níveis de lisina $(0,75 ; 0,85 ; 0,95$; 1,05 e $1,15 \%$ ) sobre a CA, que reduziu até o nível de $1,00 \%$ com um consumo total estimado de $23,90 \mathrm{~g} / \mathrm{d}$ para leitoas $(60-90 \mathrm{~kg})$ de alto potencial genético para deposição de carne magra na carcaça. Outros autores como Donzele et al. (1994), Hahn et al. (1995) e Souza (1997), utilizando leitoas em terminação, encontraram melhores respostas de CA nos níveis de 0,$83 ; 0,75$ e $0,73 \%$ de lisina, respectivamente, es tando, portanto, abaixo daquele de $0,97 \%$ observado neste trabalho.

De acordo com os resultados obtidos para melhor resposta de CA (24,23 g de lisina), pode-se inferir que a recomendação de $21,1 \mathrm{~g}$ de lisina diário, preconizada pelo NRC (1998) para leitoas $(50$ - $80 \mathrm{~kg}$ ) de alto potencial genético, é insuficiente para atender a demanda desses animais para máxima CA.

A piora na $\mathrm{CA}$, ocorrida no maior nível de lisina avaliado (1,10\%), está possivelmente relacionada ao custo extra de energia, resultante do catabolismo do excesso de aminoácidos.

Foi observado aumento linear $(\mathrm{P}<0,01)$ do consumo de lisina em razão dos níveis crescentes de lisina na dieta, segundo a equação $\hat{\mathrm{Y}}=0,0025+24,9857 \mathrm{X}$ $\left(\mathrm{r}^{2}=0,95\right)$, corroborando os resultados encontrados

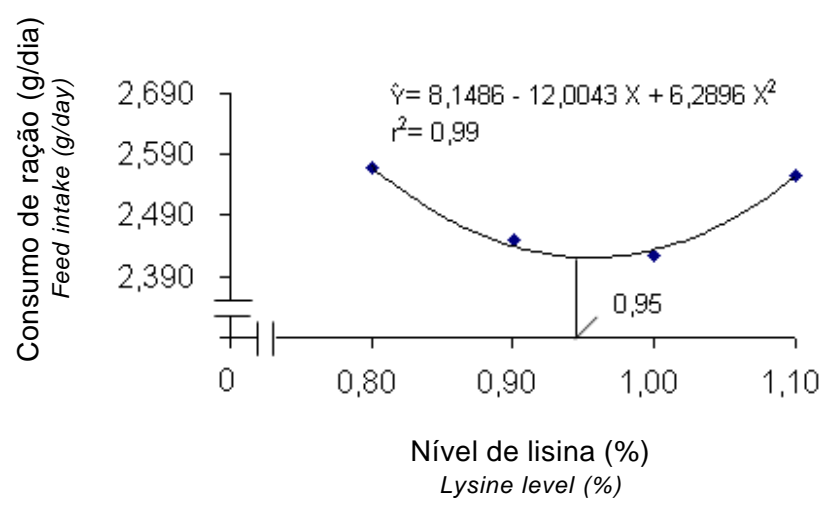

Figura 1 - Efeito do nível de lisina sobre o consumo de ração de leitoas de 65 a $95 \mathrm{~kg}$.

Figure 1 - Effect of dietary lysine level on feed intake of gilts from 65 to $95 \mathrm{~kg}$. 
por diversos outros autores (Donzele et al., 1994; Friesen et al., 1995; Souza, 1997; Fontes, 1999). Entretanto, Gomes et al. (1998), trabalhando com suínos machos castrados ( 80 - $100 \mathrm{~kg}$ ), não detectaram diferença no consumo de lisina total $(\mathrm{g} / \mathrm{d})$ em relação aos níveis de lisina testados $(0,90 ; 0,95$ e $1,05 \%)$.

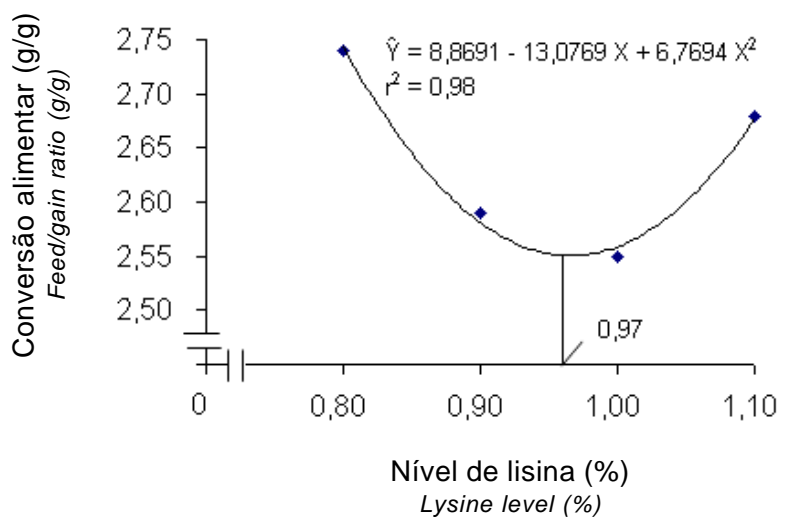

Figura 2 - Efeito do nível de lisina sobre a conversão alimentar de leitoas de 65 aos $95 \mathrm{~kg}$.

Figure 2 - Effect of dietary lysine level on feed:gain ratio of gilts from 65 to $95 \mathrm{~kg}$.
Não houve diferença $(\mathrm{P}>0,05)$ na taxa de crescimento em músculo (TCM) e na conversão alimentar em músculo (CAM) com o aumento dos níveis de lisina da dieta. Apesar de estarem em acordo com os dados obtidos por Pimenta et al. (1995) e Gomes (1998), os valores de TCM e CAM, neste experimento, foram superiores, em valor absoluto, aos encontrados por esses autores. Segundo Rao \& McCracken (1990), Friesen et al. (1994) e Pimenta et al. (1995), o potencial genético para ganho de músculo é um dos principais fatores que influem na taxa de crescimento e na conversão alimentar.

Na Tabela 3, são apresentados os resultados das taxas de deposição de proteína (TDP) e gordura (TDG) na carcaça das leitoas.

A TDP aumentou, de forma linear $(\mathrm{P}<0,01)$, com os níveis crescentes de lisina na ração (Figura 3), diferindo dos resultados obtidos por Campbell et al. (1984), Rao \& MacCracken (1990), Yen et al. (1996) e Fontes (1999), que não observaram efeito dos níveis de lisina sobre a TDP.

O valor médio $(154,62 \mathrm{~g} / \mathrm{dia})$ da TDP, obtido neste trabalho, foi próximo ao de $157 \mathrm{~g} / \mathrm{dia}$, encontrado por Fontes (1999), para leitoas (60 - $95 \mathrm{~kg})$ com alto potencial genético para deposição de carne magra. Por outro lado, Friesen et al. (1995) relataram que a TDP, para leitoas em terminação (72 aos $136 \mathrm{~kg})$, foi inferior, cerca de $30 \mathrm{~g} / \mathrm{dia}$, à de leitoas em

Tabela 3 - Taxas de deposição de proteína e gordura na carcaça de leitoas (65 e 95 kg), recebendo dietas com níveis crescentes de lisina

Table 3 - Protein and fat deposition rates in the carcass of gilts from 65 to $95 \mathrm{~kg}$, fed diets with increasing lysine levels

\begin{tabular}{|c|c|c|c|c|c|}
\hline \multirow[b]{2}{*}{$\begin{array}{l}\text { Variáveis } \\
\text { Variables }\end{array}$} & \multicolumn{4}{|c|}{$\begin{array}{c}\text { Níveis de lisina da ração (\%) } \\
\text { Dietary lysine levels }\end{array}$} & \multirow[b]{2}{*}{$\mathrm{CV}(\%$} \\
\hline & 0,80 & 0,90 & 1,00 & 1,10 & \\
\hline $\begin{array}{l}\text { Taxa de deposi } \\
\text { Deposition rate } i\end{array}$ & & & & & \\
\hline $\begin{array}{l}\text { Proteína }(\mathrm{g} / \mathrm{d})^{1} \\
\text { Protein }\end{array}$ & 148,91 & 153,10 & 153,60 & 162,88 & 8,40 \\
\hline $\begin{array}{l}\text { Gordura }(\mathrm{g} / \mathrm{d})^{1} \\
\text { Fat }\end{array}$ & 210,39 & 180,69 & 179,32 & 169,02 & 11,48 \\
\hline $\begin{array}{l}\text { Energia retida } \mathrm{n} \\
\text { Energy retained }\end{array}$ & & & & & \\
\hline $\begin{array}{l}\text { Total } \\
\text { Proteína (\%) }\end{array}$ & $\begin{array}{l}2812 \\
29,65\end{array}$ & $\begin{array}{l}2556 \\
33,54\end{array}$ & $\begin{array}{l}2546 \\
33,78\end{array}$ & $\begin{array}{l}2501 \\
36,47\end{array}$ & $\begin{array}{l}5,8 \\
5,6\end{array}$ \\
\hline $\begin{array}{l}\text { Protein } \\
\text { Gordura (\%) } \\
\text { Fat }\end{array}$ & 70,35 & 66,46 & 66,22 & 63,53 & 6,1 \\
\hline
\end{tabular}

R. Bras. Zootec., v.32, n.6, p.1647-1656, 2003 (Supl. 1) 
crescimento (34 - 72,5 kg) observados por Friesen et al. (1994). Esses autores concluíram que as diferenças apresentadas nas TDPs, entre as fases de crescimento e terminação, podem estar relacionadas ao fato de que determinados grupamentos musculares (longissimus dorsi) respondem menos eficientemente à lisina dietética com o aumento do peso corporal.

Constatou-se redução $(\mathrm{P}<0,01)$ linear TDG em função dos níveis de lisina da dieta (Figura 4), o que está de acordo com Fontes (1999), que utilizou leitoas (60 - $95 \mathrm{~kg}$ ) de alto potencial genético para deposição de carne magra.

Alguns autores observaram redução de 25\% (Fontes, 1999) a $48 \%$ (Friesen et al., 1995) na TDG de leitoas em crescimento, em relação às leitoas em terminação, quando receberam níveis crescentes de lisina na dieta. Segundo Sckinckel (1992), citado por Friesen et al. (1995), isto ocorre porque a taxa de deposição de proteína é normalmente maximizada em suínos com peso entre 40 e $50 \mathrm{~kg}$, e com o aumento do peso corporal, a taxa de deposição de gordura tende a se elevar.

As médias de rendimento de carcaça (RC), rendimento de carne magra (RCM), rendimento de gordura (RG) e rendimento de pernil (RP) das leitoas aos $95 \mathrm{~kg}$, são apresentadas na Tabela 4.

Não houve efeito $(\mathrm{P}>0,05)$ dos níveis de lisina sobre nenhuma das características de carcaça avaliadas. Esses resultados são semelhantes àqueles ob-

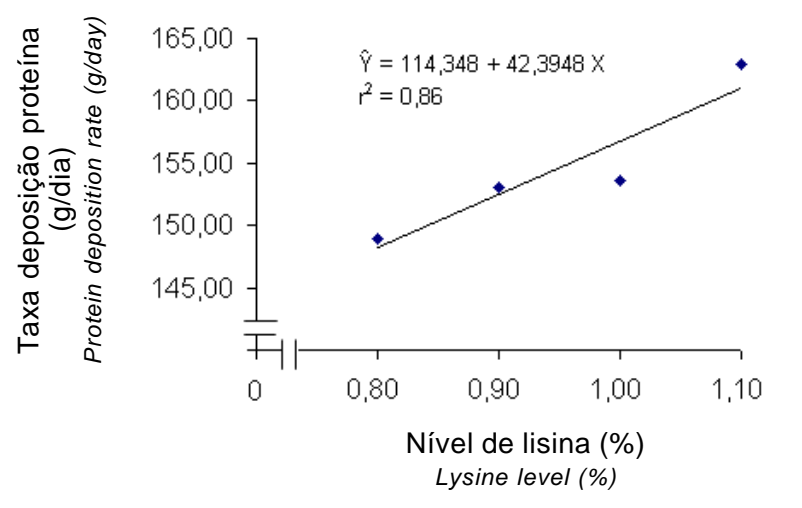

Figura 3 - Efeito do nível de lisina sobre a taxa de deposição de proteína de leitoas de 65 a $95 \mathrm{~kg}$.

Figure 3 - Effect of dietary lysine level on protein deposition rate of gilts from 65 to $95 \mathrm{~kg}$. tidos por Gomes (1998) com relação às características físicas de carcaças de suínos machos castrados, dos 30 aos $130 \mathrm{~kg}$. Considerando a pequena variação numérica $(\mathrm{P}>0,05)$ ocorrida nas características estudadas, em função dos níveis de lisina avaliados, podese deduzir que os mesmos atenderam as exigências desses animais.

Os resultados de rendimento de carcaça (RC) e comprimento de carcaça, obtidos pelo método brasileiro (CCMB), estão em acordo com os resultados determinados por Friesen et al. (1994), Hernández Villarreal (1996) e Gomes (1998). Segundo Gomes (1998), esses resultados podem ser parcialmente explicados, uma vez que espera-se pouca ou nenhuma influência da quantidade de nutrientes ingeridos, principalmente a lisina, sobre essas características.

Por outro lado, esperava-se efeito dos tratamentos sobre a espessura de toucinho (ET e P2), o rendimento de gordura (RG), o rendimento de pernil (RP) e sobre o rendimento de carne magra (RCM), que avaliam a quantidade de carne e, ou, gordura na carcaça, uma vez que está bem estabelecido, segundo diversos relatos de literatura (Cristian et al., 1980; Nunes et al., 1980; Henry et al., 1992; Castell et al., 1994, Chen et al., 1995; Irvin et al., 1995; Souza Filho, 1998), que a deposição de músculo na carcaça está relacionada com a quantidade de proteína (lisina) ingerida pelo animal.

É possível que a variação no consumo de lisina

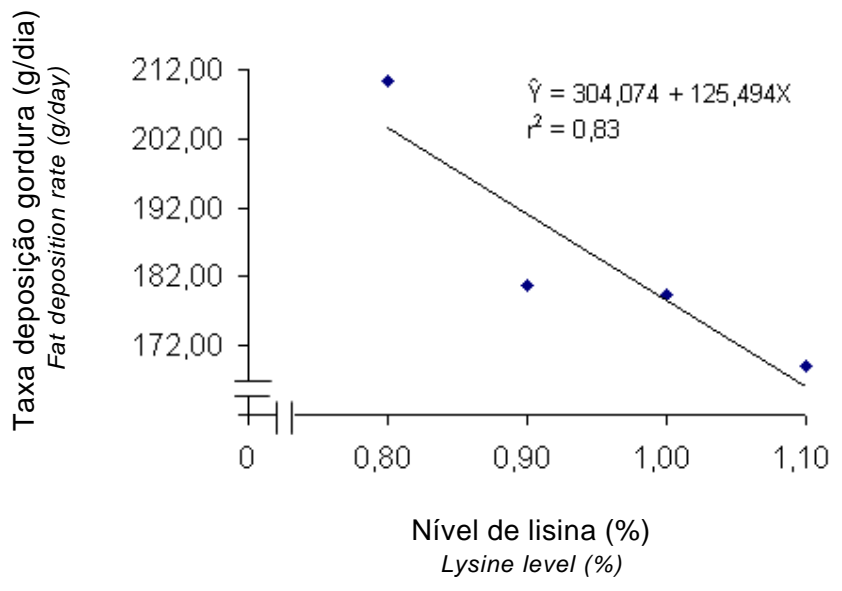

Figura 4 - Efeito do nível de lisina da dieta sobre a taxa de deposição de gordura de leitoas com alto potencial genético para deposição de carne magra, de 65 a $95 \mathrm{~kg}$.

Figure 4 - Effect of dietary lysine level on fat deposition rate of gilts with high genetic potential for lean meat from 65 to $95 \mathrm{~kg}$. 
Tabela 4 - Médias estimadas da avaliação das carcaças de leitoas (95 kg) recebendo dietas com níveis crescentes de lisina

Table 4 - Estimated means of gilts $(95 \mathrm{~kg})$ carcass traits fed diets with increasing lysine levels

\begin{tabular}{|c|c|c|c|c|c|}
\hline \multirow[b]{2}{*}{$\begin{array}{l}\text { Variáveis } \\
\text { Variables }\end{array}$} & \multicolumn{4}{|c|}{$\begin{array}{c}\text { Níveis de lisina da dieta }(\%) \\
\text { Dietary lysine levels }\end{array}$} & \multirow[b]{2}{*}{$\mathrm{CV}(\%)$} \\
\hline & 0,80 & 0,90 & 1,00 & 1,10 & \\
\hline $\begin{array}{l}\text { Comprimento de carcaça } *(\mathrm{~cm}) \\
\text { Carcass length }\end{array}$ & 95,92 & 93,17 & 94,00 & 94,34 & 2,83 \\
\hline Espessura de toucinho $* *(\mathrm{~cm})$ & 19,60 & 19,86 & 19,57 & 20,00 & 11,73 \\
\hline $\begin{array}{l}\text { Backfat thickness } \\
\mathrm{P}^{2} * * *(\mathrm{~mm})\end{array}$ & 10,00 & 10,00 & 10,86 & 11,43 & 18,92 \\
\hline $\begin{array}{l}\text { Rendimento de carcaça }(\%) \\
\text { Carcass yield }\end{array}$ & 83,40 & 81,95 & 81,99 & 82,81 & 1,29 \\
\hline $\begin{array}{l}\text { Rendimento de carne magra (\%) } \\
\text { Lean meat yield }\end{array}$ & 59,70 & 58,96 & 59,71 & 58,98 & 2,52 \\
\hline $\begin{array}{l}\text { Rendimento de gordura }(\%) \\
\text { Fat yield }\end{array}$ & 18,43 & 19,95 & 19,56 & 19,27 & 8,72 \\
\hline $\begin{array}{l}\text { Rendimento de pernil (\%) } \\
\text { Ham yield }\end{array}$ & 31,57 & 30,98 & 30,45 & 30,47 & 3,67 \\
\hline
\end{tabular}

total pelos animais, 20,54 a 28,13 g/dia, não tenha sido suficiente para alterar os resultados das características físicas de carcaça.

O resultado da análise econômica dos tratamentos é apresentado na Tabela 5.

$\mathrm{O}$ índice de rentabilidade fornece um indicativo da taxa de retorno sobre os custos, isto é, mostra o retorno líquido de cada unidade monetária gasta nas despesas ocorridas na produção.

É importante salientar que o índice de rentabilidade adotado mostrou somente o retorno sobre os gastos associados aos custos das rações. Os outros componentes do custo de produção não foram, a priori, incluídos na análise, o que não interfere na comparação entre as dietas, visto que os demais custos são idênticos para todas elas.

O estudo da análise econômica indicou que os animais, que consumiram a dieta com 1,00\% de lisina, promoveram o melhor índice de rentabilidade, de modo que, para cada $\mathrm{R} \$ 1,00$ gasto na formulação dessa dieta, obteve-se uma receita líquida de $R \$ 2,24$, desconsiderando-se os demais custos de produção. $\mathrm{O}$ retorno sobre o custo da dieta, obtido com esse tratamento $(1,00 \%$ de lisina) foi de $11 ; 1$ e 24 centavos de real, respectivamente, superior àqueles observados para os níveis de 0,80; 0,90 e 1,10\% de lisina.

Considerando os resultados de desempenho e a análise econômica, o nível de lisina de $0,97 \%$, estimado para melhor resposta de conversão alimentar, seria o mais indicado para leitoas nessa fase de crescimento. Entretanto, para a taxa de deposição de proteína, o nível de lisina parece ser maior que $1,10 \%$, uma vez que o efeito foi linear crescente.

Tabela 5 - Índice de rentabilidade de cada dieta experimental, em função dos níveis de lisina avaliados

Table 5 - Profit index of each experimental diet, in function of lysine levels

\begin{tabular}{lcc}
\hline $\begin{array}{l}\text { Níveis de } \\
\text { lisina }(\%)\end{array}$ & $\begin{array}{c}\text { Custo da } \\
\text { dieta }(\mathrm{R} \$ / \mathrm{kg}) \\
\text { Feed cost }\end{array}$ & $\begin{array}{c}\text { Índice de } \\
\text { rentabilidade (IR) } \\
\text { Profit index }\end{array}$ \\
\hline 0,80 & 0,187 & 2,13 \\
0,90 & 0,191 & 2,23 \\
1,00 & 0,195 & 2,24 \\
1,10 & 0,199 & 2,00 \\
\hline
\end{tabular}




\section{Conclusões}

Leitoas geneticamente selecionadas para alta taxa de deposição de carne magra exigem $0,97 \%$ de lisina total, correspondente ao consumo diário de 24,24 g de lisina e a 0,29\% de lisina total/Mcal de EM, para melhor conversão alimentar. Para maior taxa de deposição de proteína, os dados indicam que a exigência está acima de $1,1 \%$ de lisina total.

\section{Literatura Citada}

ASSOCIAÇÃO BRASILEIRA DE CRIADORES DE SUÍNOS - ABCS. Método Brasileiro de Classificação de Carcaça. Estrela, 1973. 17p.

BATTERHAM, E.S.; MURISON, R.D. Utilization of free lysine by growing pigs. The Bristish Journal of Nutrition, v.46, n.1, p.87-92, 1981.

BELLAVER, C.; VIOLA, E.S. Qualidade de carcaça, nutrição e manejo nutricional. In: CONGRESSO BRASILEIRO DE VETERINÁRIOS ESPECIALISTAS EM SUÍNOS, 7., 1997, Foz do Iguaçu. Anais... Foz do Iguaçu: ABRAVES, 1997. p.152-158.

BUARQUE, C. Avaliação econômica de projetos: uma apresentação didática. 8.ed. Rio de Janeiro: Campus, 1991. 266p.

CAMPABADAL, C.; NAVARRO, H. Importancia de la nutrición en la producción de canales magras de cerdo. Medellín, Colombia: Associación Americana de Soya. SOYANOTICIAS, 1997.

CAMPBELL, R.G.; TAVERNER, M.R.; CURIC, D.M. Effects of feeding level and dietary protein content on the growth, body composition and rate of protein deposition in pigs growing from 45 to $90 \mathrm{~kg}$. Animal Production, v.38, p.233, 1984.

CASTELL, A.G.; CLIPLET, R.L.; POSTE-FLYNN, L.M. et al. Performance, carcass and pork characteristics of castrates and gilts self-fed differing in protein content and lysine: energy ratio. Canadian Journal of Animal Science, v.74, n.3, p.519-528, 1994.

CHEN, H.Y.; MILLER, T.S.; LEWIS, A.J. et al. Changes in plasma urea concentration can be used to determine protein requirements of two populations of pigs with different protein acretion rates. Journal of Animal Science, v.73, n.9, p.2631-2639, 1995.

CRISTIAN, L.L.; STROCK, K.L.; CARLSON, J.P. Effects of protein, breed cross, see and slanghter weight of swine performance and carcass traits. Journal of Animal Science, v.51, n.1, p.51-58, 1980.

CROMWELL, G.L.; CLINE, T.R.; CRENSHAW, J.D. et al. The dietary protein and (or) lysine requirements of barrws and gilts. Journal of Animal Science, v.71, n.6, p.1510-1519, 1993.

DONZELE, J.L.; FREITAS, R.T.F.; OLIVEIRA, R.F.M. et al. Níveis de lisina para leitoas de 30 a $60 \mathrm{~kg}$ de peso vivo. Revista da Sociedade Brasileira de Zootecnia, v.24, n.6, p.967-973, 1994.

EASTER, R.A.; BAKER, D.H. Lysine and protein level in cornsoybean meal diets for growing swine. Journal of Animal Science, v.50, n.3, p.467-471, 1980.

FONTES, D.O. Lisina para leitoas selecionadas genetica- mente para deposição de carne magra na carcaça, dos 15 aos 90 kg. Viçosa, MG: Universidade Federal de Viçosa, 1999.101p. Tese (Doutorado em Zootecnia) - Universidade Federal de Viçosa, 1999.

FOWLER, V.R.; BICHARD, M.; PEASE, A. Objectives in pig breeding. Animal Production, v.23, n.3, p.365-387, 1976.

FRIESEN, K.G.; NELSSEN, J.L.; GOODBAND, R.D. et al. Influence of dietary lysine on growth and carcass composition of high-lean-growth gilts fed from 34 to 72 kilograms. Journal of Animal Science, v.72, p.1761-1770, 1994.

FRIESEN, K.G.; NELSSEN, J.L.; GOODBAND, R.D. et al. The effect of dietary lysine on growth, carcass composition, and lipid metabolis $m$ in high-lean growth gilts fed from 72 to 136 kilograms. Journal of Animal Science, v.73, p.3392-3401, 1995.

FULLER, M. Macronutrient requirements of growing swine. In: SIMPÓSIO INTERNACIONAL SOBRE EXIGÊNCIAS NUTRICIONAIS DE AVES E SUÍNOS, 1996, Viçosa, MG. Anais...Viçosa: UFV, 1996.

GATEL, F.; FEKETE, J. Lysine and threonine balance and requirements for weanwed piglets $10-25 \mathrm{~kg}$ live weight fed cereal based diets. Livestock Production Science, v.23, p.195-206, 1989.

GOMES, F.E. Planos de nutrição baseados em níveis de lisina para suínos de diferentes genótipos abatidos aos 80 e 100 kg de peso vivo. Lavras, MG: UFLA, 1998.55p. Dissertação (Mestrado em Zootecnia) - Universidade Federal de Lavras, 1998.

HAHN, J.D.; BIEHL, R.R.; BAKER, D.H. Ideal digestible lysine level for-early and late-finishing swine. Journal of Animal Science, v.73, n.3, p.773-784, 1995.

HENRY, Y.; COLLÉAUX, Y.; SÉVE, B. Effects of dietary level of lysine and of level and source of protein on feed intake, growth performance, and plasma amino acid pattern in the finishing pig. Journal of Animal Science, v.70, n.1, p.188-195, 1992.

VILLARREAL, L.A. Planos de nutrição influenciando as características de carcaça de suínos. Lavras: UFLA, 1996. 58p. Dissertação (Mestrado em Zootecnia) - Universidade Federal de Lavras, 1996

IRVIN, K.M.; SWIGER, L.A.; MAHAN, D.C. Influence of dietaryprotein level on swine with different growth capabilities. Journal of Animal Science, v.73, n.5, p.1031-1047. 1995.

LAURENCE, B.V.; ADEOLA, O.; CLINE, T. R. Lean growth response of pigs fed diets balanced on a lysine to digestible energy basis from 50 to $110 \mathrm{~kg}$.Journal of Animal Science, v.72, p.216 (Suppl. 1), 1994a.

LAWRENCE, B.V.; ADEOLA, O.; CLINE, T.R. Nitrogen utilization and lean growth performance of 20 to 50 kilogram pigs fed diets balance for lysine: energy ratio. Journal of Animal Science, v.72, n.11, p.2887-2895, 1994b.

MARINHO, S.F. Exigência nutricional de lisina e avaliação de rações formuladas com valores de lisina total e digestível para suíns em terminação. Viçosa, MG: Universidade Federal de Viçosa, 1990. 81p. Dissertação (Mestrado em Zootecnia) - Universidade Federal de Viçosa, 1990.

MARTINEZ, G.M.; KNABE, D.A. Digestible lysine requirement of starter and grower pigs. Journal of Animal Science, v.68, p.2748-2755, 1990.

NATIONALRESEARCHCOUNCIL - NRC. Committee on Animal Nutrition. Subcommittee of Swine Nutrition. Nutrient requirements of swine. 10.ed., Washington: National Academic of Sciences, 1998. 189p. 
NUNES, J.R.V.; LOPES, J.E.; NICOLAIEWSKY, S. Desempenho e características de carcaça de machos inteiros e castrados sob dietas com dois níveis de proteína. Revista Brasileira de Zootecnia, v.9, n.1, p.1-9. 1980.

PIMENTA, M.E.S.G. Planos de nutrição para suínos de dois genótipos com pesos diferentes de abate.Lavras: Universidade Federal de Lavras, 1995. 66p. Dissertação (Mestrado em Zootecnia) - Universidade Federal de Lavras, 1995.

RAO, D.S.; McCRACKEN, K.J. Effects of protein intake on energy and nitrogen balance and chemical composition of gain in growing boars of high genetic potential. Animal Production, v.51, p.389-397, 1990.

ROSTAGNO, H.S.; SILVA, D.J.; COSTA, P.M.A. et al. Composição de alimentos e exigências nutricionais de aves e suínos (Tabelas brasileiras). Viçosa, MG: Universidade Federal de Viçosa, 1992. 59p.

ROSTAGNO, H.S.; ALBINO, L.F.T.; DONZELE, J.L. et al. Composição de alimentos e exigências nutricionais(Tabelas brasileiras para aves e suínos). Viçosa, MG: Universidade Federal de Viçosa, 2000. 141p.

SCHINCKEL, A.P. Nutrient requirements of modern pig genotypes. In: GARNSWORTHY, P.C.; COLE, D.J.A. (Eds.) Recent advances in animal nutrition. Nottingham: Nottingham University Press, 1994. 291p.

SILVA, D.J. Análise de alimentos: métodos químicos e biológicos. 2.ed. Viçosa, MG: Universidade Federal de Viçosa, 1990. 166p.

SOUZA, A.M. Exigências nutricionais de lisina para suínos mestiços, de 15 a $95 \mathrm{~kg}$ de peso. Viçosa, MG: Universidade Federal de Viçosa, 1997. 81p. Dissertação (Mestrado em Zootecnia) - Universidade Federal de Viçosa, 1997.
STAHLY, T.S.; CROMWELL, G.L.; TERHUME, D. Responses of high, medium and low lean growth genotypes to dietary amino acid regimen. Journal of Animal Science, v.69, p.364 (Abstr.), 1991. (Suppl. 1)

STAHLY, T.S.; WILLIAMS, N.H., SWENSON, S. Impact of genotype and dietary amino acid regimen on growth of pigs from 6 to $25 \mathrm{~kg}$. Journal of Animal Science, v.69, p.165, 1994. (Suppl. 1)

UNIVERSIDADE FEDERAL DE VIÇOSA - UFV. SAEG (Sistemas de Análises Estatísticas e Genéticas). Viçosa, MG (Versão 8.0). 2000.

YEN, H.T.; COLE, D.J.A.; LEWIS, D. Amino acid requirements of growing pigs. 7. The response of pigs from 35 to $35 \mathrm{~kg}$ live weight to dietary ideal protein. AnimalProduction, v.43, n.3, p.141-154, 1986.

YEN, J.P., KLINDT, J., KERR, B.J. et al. Lysine requirement in finishing pigs treated with porcine somatotropin by sustainedrelease implant. Journal of Animal Science, v.74, p.196, 1996. (Suppl. 1). 